\title{
Numerical Investigation on Freezing in Ballast Tank of Ship Navigating in Ice-bound Sea
}

\author{
Ho-Keun Kang*, Ki-Pyoung Kim* and Soo-Whan Ahn ${ }^{* *} \dagger$
}

(received 30 November 2012, revised 04 January 2013, accepted 18 January 2013)

\begin{abstract}
For vessels operating in the cold climate regions, the ballast water inside or hopper tanks above the waterline may be frozen, starting at the top of the tank and at the side walls. Therefore, countermeasures against freeze-up of the ballast tank such as air-bubbling system, hot steam injecting system, heating coil system and water circulating system are taken to prevent freeze-up phenomenon; however, there are no rigorous investigations of anti-freezing to examine the effectiveness and validity of systems against freeze-up of the ballast tank, in which the temperatures are about $-25^{\circ} \mathrm{C}$ (ambient air temperature) and $0^{\circ} \mathrm{C}$ (sea water), respectively. In this paper, to ensure reasonable specifications for cold regions if the measures from the above-mentioned systems against freeze-up are effective, the phenomenon of ballast tank freeze-up is simulated and discussed in low temperature conditions. With the results using the commercial CFD code, CFX 14, the most cost-effective solution is conducted to prevent being frozen along the outer surface.
\end{abstract}

Key Words : Winterization, Freeze-up, Ballast Water, CFD

\section{- Nomenclature -}

$C_{\mu}, C_{\varepsilon 1}, C_{\varepsilon 2}:$ Empirically determined coefficients in k- $\varepsilon$ model

$i_{\text {tot }} \quad$ : Total enthalpy, $[\mathrm{J} / \mathrm{kg}]$

$P \quad$ : Turbulence production due to shear stress

$\begin{array}{ll}p & : \text { Pressure, }[\mathrm{kPa}] \\ T & : \text { Temperature, }\left[{ }^{\circ} \mathrm{C}\right]\end{array}$

$t \quad$ : Time, [s]

$U \quad$ : Flow velocity, $[\mathrm{m} / \mathrm{s}]$

**†Soo-Whan Ahn(corresponding author) : Department of Mechanical and System Engineering, Institute of Marine Industry, Gyeongsang National University.

E-mail : ahn9294@gnu.ac.kr, Tel : 055-772-9105

*Ho-Keun Kang, Ki-Pyoung Kim : Institute of Ship \& Ocean Systems Engineering, Korean Register of Shipping.

\section{Greek Symbols}

$\varepsilon \quad:$ Turbulence dissipation

$\kappa \quad$ : Kinetic energy of turbulent

fluctuations

$\mu_{\text {eff }} \quad:$ Effective eddy viscosity

$\rho \quad$ : Density, $\left[\mathrm{kg} / \mathrm{m}^{3}\right]$

$\sigma_{k}, \sigma_{\varepsilon} \quad$ : Empirically determined coefficients in $k$ - $\varepsilon$ model

\section{Introduction}

The low-temperature of the ice-bound sea through which the vessels are to sail require special measures for the hull structure, the outfittings and etc. Furthermore, in recent years, there have been 
substantial interest and demand for ships to navigate in cold region. Ships assumed to sail in atmospheric temperatures of about -10 to $-20^{\circ} \mathrm{C}$ in LMDAT(Lowest Mean Daily Average Temperature) and about -30 to $-40^{\circ} \mathrm{C}$ falling in category of Extreme Temperature. So many features fitted to these ships to combat the low temperatures and icing are needed for ice class requirements, and these are based on experience of operations.

When the rules or regulations are still being defined for the design of outfittings for ships in accordance with specifications for cold districts, various parties propose specific measures to fulfil the requirements. When designing the outfittings, it is crucial to secure safety, reliability, and a reasonable design all at once in a well and reasonably balanced manner according to the required low-temperature environment.

The extremely cold environment of the Arctic and the Antarctic could cause the ballast water, air and vent pipes, valves and section lines to be frozen. It is unlikely that any sizeable tank will be frozen solid since ice acts as an insulator; however, ice cannot be discharged when the vessel is loading and causes the deadweight capacity to be reduced.

Arrangements are to be provided to prevent water ballast being frozen in tanks adjacent to the shell and located totally or partly above the ballast water line.

There are many systems to prevent ice formation in ballast tanks, and the followings are major systems:

- Heating systems

- Internal circulating / pumping systems

- Air-bubbling systems

- Steam injection systems

One conceivable method to prevent the ballast water from being frozen is to heat it with steam or hot water. But this method would force the
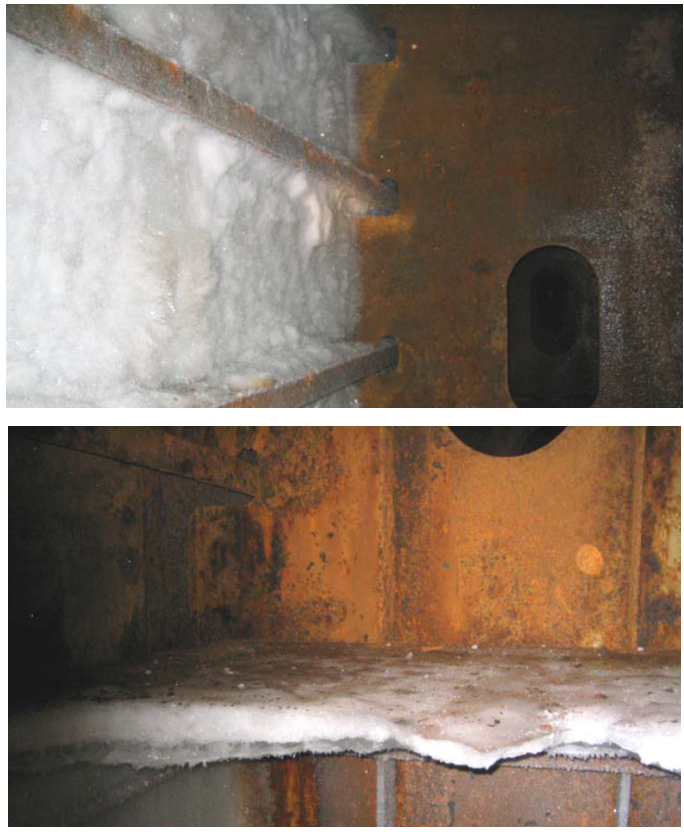

Fig. 1 Freezing of ballast water

customer to invest in expensive measures to prevent water being frozen in ballast tanks.

The most effective and commonly used is steam heating coils. The heating coils are usually fitted above the ballast waterline adjacent to the ships side shell. Makkonen ${ }^{1)}$ indicates that heating is not practical for anti-icing or de-icing because of the large amount of energy necessary for latent heat. This approach would force the customer to invest in expensive measures to prevent the seawater from corroding the steam pipe, either by using a pipe material with high corrosion resistance from the beginning or by using general steel pipes based on the premise of the maintenance during service ${ }^{2)}$. Circulating the ballast water is considered an efficient alternative method because of the natural differences in temperatures in the tank. Moreover air bubbling system achieves the same effect as the circulation. Koo et al. $^{3)}$ performed numerical simulation to investigate the effectiveness of the air bubbling system used for winterization design 
concept for ballast tank. Through their results, it became clear that the air bubbling system equipped in each frame of water ballast tanks was effective to prevent being frozen along the outer surface by promoting convective heat transfer. Furthermore, Jeong et al. ${ }^{4}$ carried out anti-icing performance tests for the ballast water using micro-bubble system and sea water circulation system at two temperature conditions $\left(-10^{\circ} \mathrm{C}\right.$ and $\left.-25^{\circ} \mathrm{C}\right)$. And the investigation of fluid flows and heat transfer in the fluidized bed heat exchanger for the ship were conducted. $^{5-6)}$

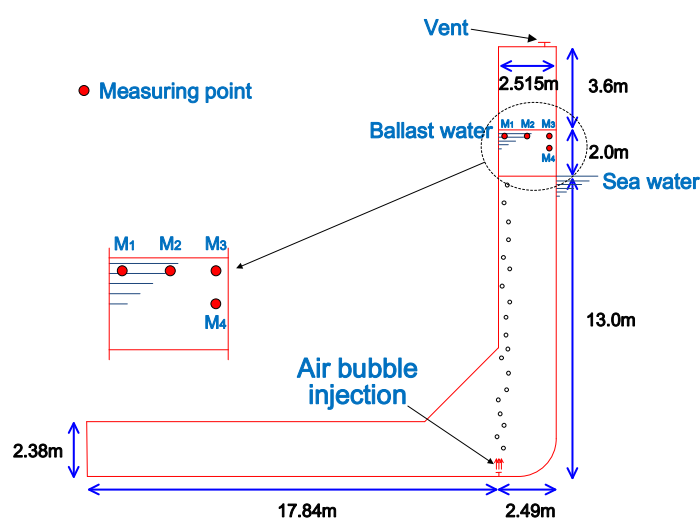

(a) Air bubbling system

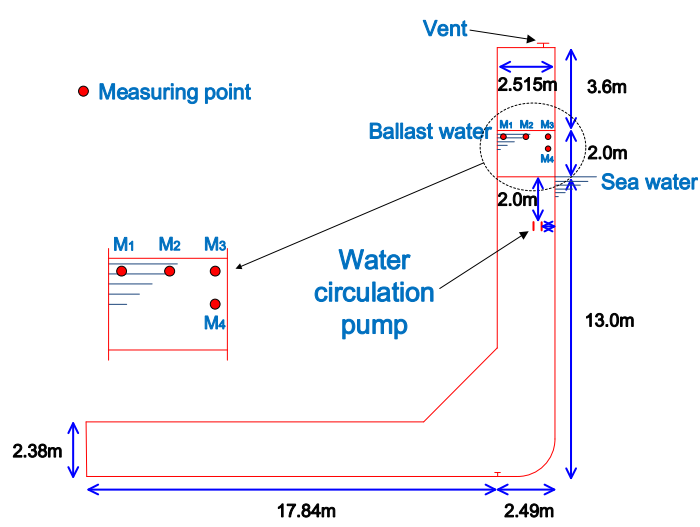

(b) Water circulating systems

Fig. 2 Schematic of a ballast tank in a typical container ship.
In this paper, to take measures the above stated systems such as the air-bubbling system and the water circulating system, the phenomenon of ballast tank freeze-up is simulated and discussed in low temperature environment if the countermeasures against the freeze-up can be confirmed for an actual need to do so.

\section{Numerical method}

The transient numerical simulations of the fluid flow and heat transfer in the analyzed ballast geometries were performed with the CFX 14 commercial code. Figure 2 shows a schematic of a ballast water tank consisting of an air inlet at the bottom, a long base, turning section, vertical rise section and exit port. The shape and intricate internal geometry of the tanks is at present entirely driven by structural consideration of the vessel. The density of sea water depends on both salinity and temperature, but lies typically within a range of $1,024 \sim 1,030 \mathrm{~kg} / \mathrm{m}^{3}$.

The governing equation used in our numerical study consisted of the 3-dimensional, unsteady, time-dependent continuity, momentum and energy equations. The two-equation $k-\varepsilon$ turbulence model was used to obtain the Reynolds stresses based on the eddy viscosity introduced in the Boussinesq approximation. In general, turbulence models seek to modify the original unsteady Navier-Stokes equations by introducing averaged and fluctuating quantities to produce the RANS equations. The values of $k$ and $\varepsilon$ derived directly from differential transport equations for the turbulence kinetic energy and turbulence dissipation rate are shown in Table 1. The temperature field was calculated using an eddy diffusivity approximation for the turbulent heat flux. 
Table 1 Governing equation and coefficients

Continuity equation:

$\frac{\partial \rho}{\partial t}+\nabla \cdot(\rho \mathbf{U})=0$

Momentum equation:

$\frac{\partial \rho \mathbf{U}}{\partial t}+\nabla \cdot(\rho \mathbf{U} \otimes \mathbf{U})-\nabla \cdot\left(\mu_{e f f} \nabla \mathbf{U}\right)=\nabla p^{\prime}+\nabla \cdot\left(\mu_{e f f} \nabla U\right)^{T}+B$

Energy equation:

$\frac{\partial \rho i_{t o t}}{\partial t}+\nabla \cdot\left(\rho U i_{t o t}+\rho \overline{\mathbf{u} i}-\lambda \nabla T\right)=\frac{\partial p}{\partial t}$

Turbulent kinetic energy equation:

$\frac{\partial(\rho k)}{\partial t}+\nabla \cdot(\rho \mathbf{U} k)=\nabla \cdot\left[\left(\mu+\frac{\mu_{t}}{\sigma_{k}}\right) \nabla k\right]+P_{k}-\rho \varepsilon$

Dissipation rate equation of turbulent kinetic energy:

$\frac{\partial(\rho \varepsilon)}{\partial t}+\nabla \cdot(\rho \mathbf{U} \varepsilon)=\nabla \cdot\left[\left(\mu+\frac{\mu_{t}}{\sigma_{\varepsilon}}\right) \nabla \varepsilon\right]+\frac{\varepsilon}{k}\left(C_{\varepsilon 1} P_{k}-C_{\varepsilon 2} \rho \varepsilon\right)$

Effective eddy viscosity and shear production of turbulence:

$\mu_{\text {eff }}=\mu+\mu_{t}, \quad P_{k}=\mu_{t} \nabla \mathbf{U} \cdot\left(\nabla \mathbf{U}+\nabla \mathbf{U}^{T}\right)-\frac{2}{3} \nabla \cdot \mathbf{U}\left(3 \mu_{t} \nabla \cdot \mathbf{U}+\rho k\right)$

where,

$C_{\mu}=0.09, C_{\varepsilon 1}=1.44, C_{\varepsilon 2}=1.92, \mu_{t}=\frac{\rho C_{\mu} k^{2}}{\varepsilon}, \sigma_{k}=1.0, \sigma_{\varepsilon}=1.3$

Table 2 Initial conditions for numerical simulation

\begin{tabular}{|c|c|c|c|c|}
\hline & Ballast water conditions & $\begin{array}{c}\text { Ambient } \\
\text { temperature }\end{array}$ & $\begin{array}{c}\text { Ballast } \\
\text { temperature }\end{array}$ & $\begin{array}{l}\text { Sea water } \\
\text { temperature }\end{array}$ \\
\hline Case I & & $-25^{\circ} \mathrm{C}$ & $0^{\circ} \mathrm{C}$ & $0{ }^{\circ} \mathrm{C}$ \\
\hline Case II & & $-25^{\circ} \mathrm{C}$ & $10^{\circ} \mathrm{C}$ & $5^{\circ} \mathrm{C}$ \\
\hline Case III & $\begin{array}{l}\text { Air bubble injection } \\
\text { - Mean diameter : } 0.006 \mathrm{~m} \\
\text { - Mass flow rate }: 0.006962 \mathrm{~kg} / \mathrm{s}\end{array}$ & $-25^{\circ} \mathrm{C}$ & $0^{\circ} \mathrm{C}$ & $0^{\circ} \mathrm{C}$ \\
\hline Case IV & $\begin{array}{l}\text { Air bubble injection } \\
\text { - Mean diameter : } 0.006 \mathrm{~m} \\
\text { - Mass flow rate }: 0.006962 \mathrm{~kg} / \mathrm{s}\end{array}$ & $-25^{\circ} \mathrm{C}$ & $10^{\circ} \mathrm{C}$ & $5^{\circ} \mathrm{C}$ \\
\hline Case V & $\begin{array}{l}\text { Water circulation } \\
\text { - Nozzle diameter : } 0.3 \mathrm{~m} \\
\text { - Water velocity : } 2.0 \mathrm{~m} / \mathrm{s}\end{array}$ & $-25^{\circ} \mathrm{C}$ & $10^{\circ} \mathrm{C}$ & $5^{\circ} \mathrm{C}$ \\
\hline
\end{tabular}

\section{Results and discussion}

The freezing point of water containing the salt depends on salinity. The greater the salinity becomes, the lower the freezing point of sea water is gotten. Sea water with salinity of 35 parts per thousand or corresponding specific gravity of 1.025 to be frozen at $-3^{\circ} \mathrm{C}\left(28.6^{\circ} \mathrm{F}\right)$ or lower. 


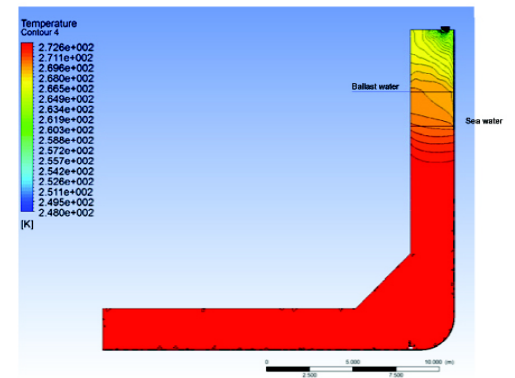

(a) 51 minutes (Case I)

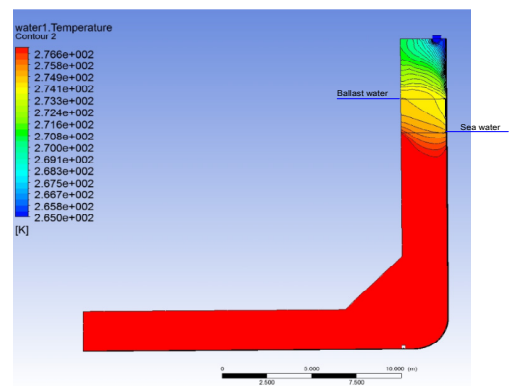

(b) 177 minutes (Case II)

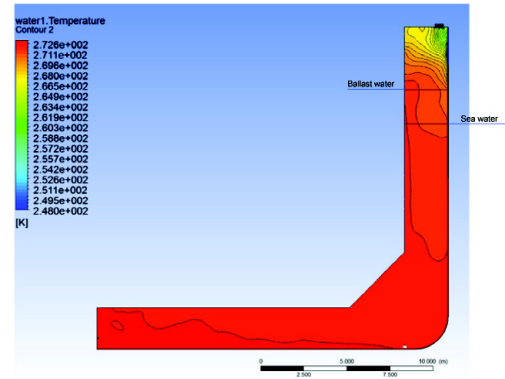

(c) 101 minutes (Case III)

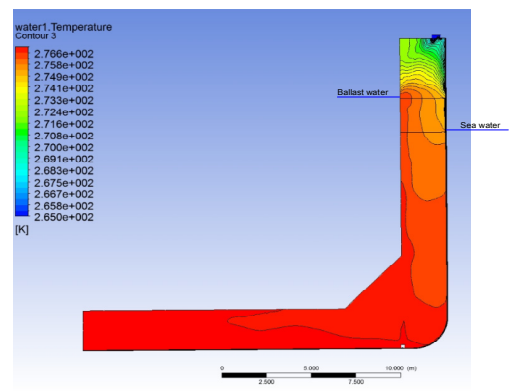

(d) 446 minutes (Case IV)

Fig. 3 Temperature distributions in ballast tank about 51(Case I), 177(Case II), 101(Case III) and 446(Case IV) minutes after the simulation starts.

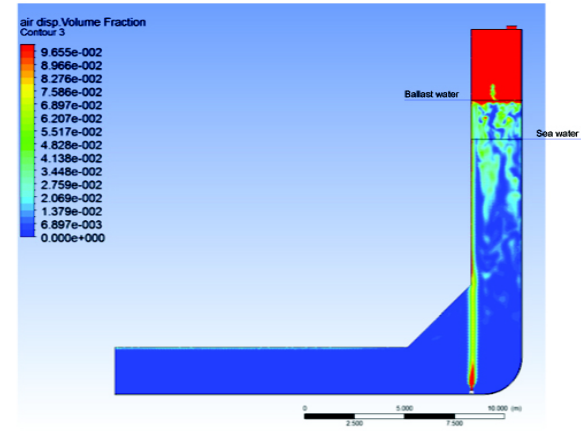

(a) 101 minutes (Case III)

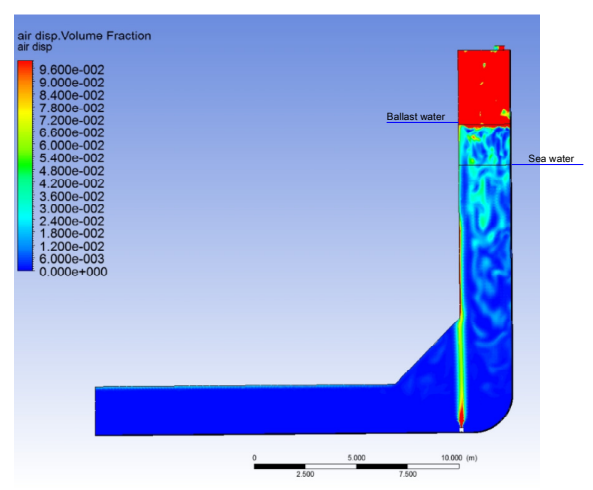

(b) 446 minutes (Case IV)

Fig. 4 Flow patterns with air volume fraction due to a continuous spouting of air bubbles up from the bottom of the ballast tank.

\subsection{Effects of air-bubbling systems in the ballast tank}

The air-bubbling ice-prevention systems keep the water in motion and carry warm water upward from the motion. In this method, the formation of ice on the surface is prevented naturally. To examine the effects of the air-bubbling ice-prevention system and the water-circulating ice-prevention system, 5 cases are considered, as presented in Table 2. Figures 3(a) to (d) show the numerical observations of temperature fields and time variations in the ballast tank, where the time corresponds to 51, 177, 101 and 446 minutes, respectively. In the figure, Case III and IV in Figs. 
3(c) and (d) are the case of anti-freezing equipment such as an air-injected system, and Case I and II in Figs. 3(a) and (b) are not equipped with the air bubbling system. Even though the temperatures of ambient air and sea water are $-25^{\circ} \mathrm{C}$ and around $0^{\circ} \mathrm{C}$, respectively, the air-bubbling system effectively prevents ballast water from being frozen by the circulation of ballast water due to the air bubble trajectories without any heating units, as shown in the Figs. 4(a) and (b).

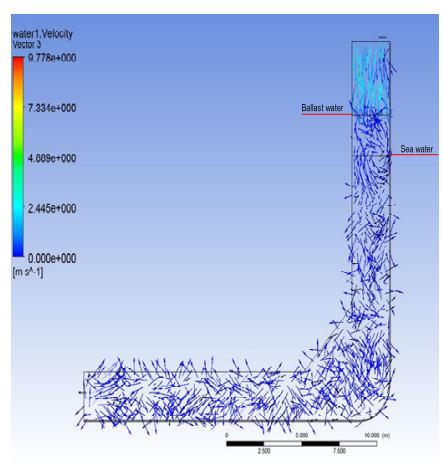

(a) Case I (51 min)

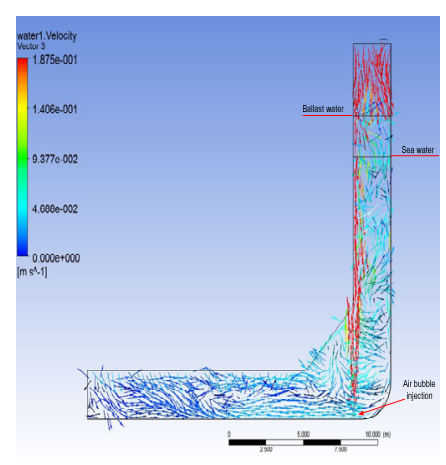

(b) Case III (101 min)

Fig. 5 Velocity vectors for Case I and Case II, respectively.

Figures 5(a) and (b) show the flow patterns with velocity vectors for Case I and Case III, respectively. In the Fig. 5(b), in the case of preventing ballast water in a ship navigating in the in- tense cold area from being frozen by introducing the compressed air through an air nozzle and then discharging it from the bottom of each ballast tank, the cold water in an upper layer may be replaced with hot water in a lower layer with the use of convention due to ascending of bubbles produced by discharged compressed air. With this arrangement such as air-bubbling ice-prevention system, it is possible to effectively prevent ballast water in a ship navigating in the cold regions from being frozen. Figure 6 shows the time variations of

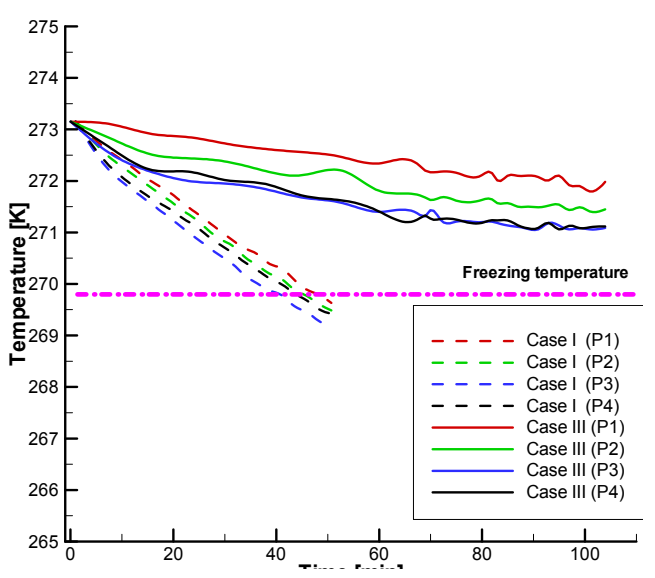

(a) Case I and Case III

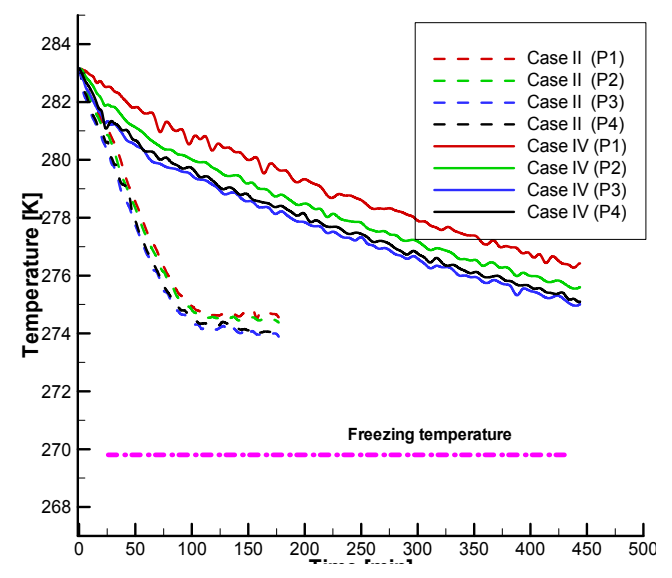

(b) Case II and Case IV

Fig. 6 Time variation of temperature change in the ballast tank at 4 monitoring points 
temperature change after simulations start at 4 monitoring points, as shown in Fig. 2. In the Case I of Fig. 6(a), the freezing temperature was reached after 46 minutes, but the case with air bubbling system (Case III or Case IV) didn't drop below freezing sea water temperature in the ballast tank. The reason is that a continuous spouting of air bubbles up from the bottom of the ballast tank can effectively prevent blockage of flow in the tank. The force of the air bubbles can be expected to break up ice as it forms. The bubbles also help to melt the ice by bringing up the warmer seawater from the bottom of the tank, as shown in Fig. 4 and Fig. 5(b).

\subsection{Effects of the applied ice-prevention systems in ballast tank}

The air-bubbling ice-prevention system and the water-circulating ice-prevention system keep the water in motion and are substituted with warm water upward from the motion. Consequently, the surface of water is agitated continuously to prevent the tank from being frozen.

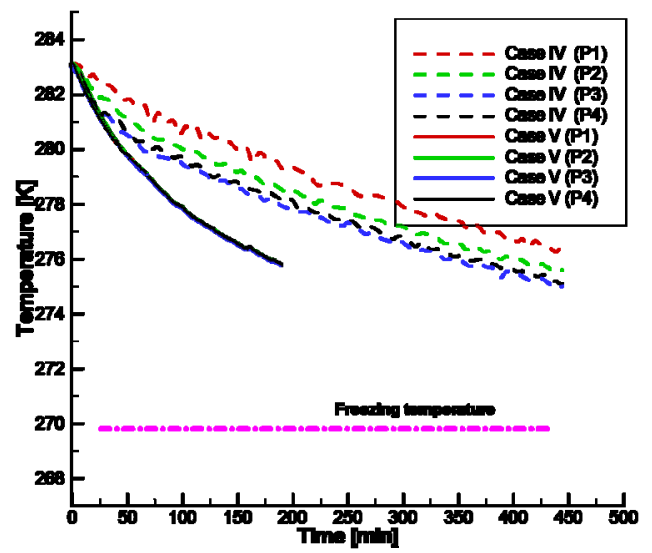

Fig. 7 Comparison of the anti-freezing effectiveness between air-bubbling system and water-circulating system in ballast tank.
Figure 7 shows the time variations for temperature change at 4 monitoring points for the air-bubbling system and the water-circulating system. Moreover, Figs. 8(a) and (b) represent the flow patterns for both cases. In Fig. 8(a), the continuous air bubbles up from the bottom of the ballast tank bring up overall the warmer seawater

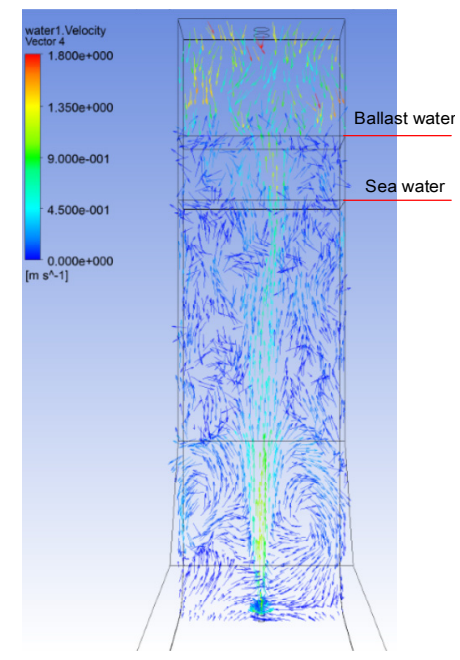

(a) 446 minutes (Case IV)

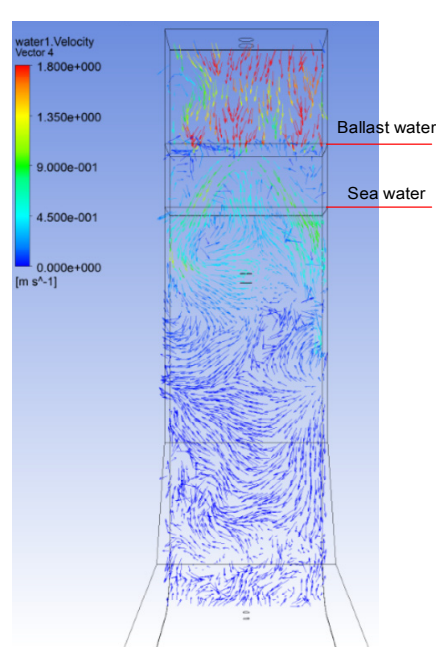

(b) 63 minutes (Case V)

Fig. 8 Velocity vectors for Case IV(air-bubbling system) and Case V(water-circulating system). 
with the force of air bubble, but the water in the circulating system just circulates at the upper side of ballast tank. Hence, it is believed that the bubble ice-prevention system is more effective than that of the water circulating one.

In conclusion, the numerical simulation demonstrates that water in the tank may make it possible for the empty bilge and ballast tank not to be frozen. Fore peak and after peak ballast tanks are particularly vulnerable to being frozen as they are often exposed to the ambient air temperature, being mostly above the waterline. Wing ballast tanks extending above the waterline are also vulnerable to being frozen, and any ballast tanks filled with fresh water will be frozen more quickly than those of containing sea water. If ballast tanks are pressed-up with any standing water in the air vent pipes and sounding pipes, these pipes may be frozen, preventing the ballast from being pumped. The ship design should be ensured that the freeze-up is minimized or eliminated by judicious arrangements of the tanks and pipings, and selections of valves and heating systems.

\section{Conclusions}

Vessels sailing in cold districts must be designed not only with sufficient strength against ice, but also adequate winterization countermeasures at low temperature about -10 to $-20^{\circ} \mathrm{C}$ in LMDAT and -20 to $-30{ }^{\circ} \mathrm{C}$ in the extreme temperature. Then the anti-freezing systems, such as ballast water circulating system and air bubbling system, have been used to the ballast tank navigating in cold region.

In this paper, numerical investigations were conducted to examine effectiveness of the air-bubbling ice-prevention system and the water-circulating ice-prevention system applied to winterization of ballast tank for ships operating in polar waters. Through the results, it became clear that ballast water circulating countermeasures such as the air-bubbling ice-prevention system help to prevent or slow its freezing, and effectively protects ballast water from being frozen by the circulation of ballast water due to the air bubbles trajectories without any heating system.

\section{References}

1. L. Makkonen, 1984, "Atmospheric icing on sea structures", US Army Cold Regions Research and Engineering Laboratory, Hanover, New Hampshire, CRREL Monograph 84-2.

2. S. Hiramatsu et al., 2007, "Features of the latest LNG carriers sailing into low-temperature environments", Mitsubishi Heavy Industries, Ltd. Technical Review Vol. 44, No. 3.

3. M. J. Koo et al., 2007, "Fluid flow and heat transfer analysis on freezing in water ballast tank", Journal of the Society of Naval Architects of Korea, Vol. 44, No. 2.

4. S. Y. Jeong et al., 2011, "A study on anti-icing technique for ballast water of icebreaking vessels operating in ice-covered water", Journal of the Society of Naval Architects of Korea, Vol. 48, No. 1.

5. S. W. Ahn, B. C. Lee and H. K. Kang 2007, "Effects of particle concentrations on friction factors and pressure drops in a horizontal pipe", Journal of the Korean Society for Power System Engineering, Vol. 11, No. 4, pp. 44-49.

6. B. C. Lee, H. K. Kang, M. S. Lee and S. W. Ahn, 2012, "Numerical analysis of fluid flow and thermal field in the vertical fluidized bed heat exchanger", Journal of the Korean Society for Power System Engineering, Vol. 16, No. 4, pp. 24-29 